\title{
EFFECTS ON BREAD AND OIL QUALITY AFTER FUNCTIONALIZATION WITH MICROENCAPSULATED CHIA OIL
}

\author{
Agustín González $^{1,2}$, Marcela L. Martínez ${ }^{3,4}$, Alberto E. León ${ }^{5}$, Pablo D. Ribotta ${ }^{5 *}$
}

${ }^{1}$ Universidad Nacional de Córdoba, Facultad de Ciencias Químicas, Laboratorio de Materiales Poliméricos (LaMaP). Córdoba, Argentina.

${ }^{2}$ Instituto de Investigaciones y Desarrollo en Ingeniería de Procesos y Química Aplicada (IPQA). CONICET. Córdoba, Argentina.

${ }^{3}$ Instituto de Ciencia y Tecnología de los Alimentos-Córdoba (ICTA-FCEFyN-UNC). Córdoba, Argentina.

${ }^{4}$ Instituto Multidisciplinario de Biología Vegetal (IMBIV-CONICET). Córdoba, Argentina.

${ }^{5}$ Instituto de Ciencia y Tecnología de los Alimentos Córdoba (ICYTAC-CONICET). Córdoba, Argentina.

*Corresponding author: Pablo D. Ribotta.

Email address: pribotta@agro.unc.edu.ar

Postal address: Juan Filloy s/n - Ciudad Universitaria - Córdoba (X5000HUA), Argentina.

Tel-Fax: +54-351-4629520.

\begin{abstract}
BACKGROUND: Omega-3 and omega-6 fatty acids-rich oils suffer oxidation reactions that alter their chemical and organoleptic quality. However, microencapsulation can be a powerful
\end{abstract} This article has been accepted for publication and undergone full peer review but has not been through the copyediting, typesetting, pagination and proofreading process which may lead to differences between this version and the Version of Record. Please cite this article as doi: $10.1002 /$ jsfa. 9022 
tool for its protection against ambient conditions. The addition of microencapsulated chia oil as an ingredient in bread preparation and its effect on the technological and chemical quality of breads was studied in this work.

RESULTS: Microencapsulation of chia oil was carried out by freeze-drying with soy proteins as wall material and the oil release was determined in in-vitro gastric and intestinal conditions. Encapsulated oil-containing bread showed no differences in specific volume, average cell area, firmness and chewiness with respect to control bread. Unencapsulated oil-containing bread showed a marked increase in hydroperoxide values respect to control, while encapsulated oilcontaining bread values were not affected by baking and bread storage. The fatty acid profiles showed a decrease of $13 \%$ and $16 \%$ in \pm -linolenic acid in the encapsulated and unencapsulated oils with respect to bulk chia oil. Sensory analysis showed no significant differences between bread samples.

CONCLUSIONS: The addition of encapsulated chia oil did not alter the technological quality of breads and prevented the formation of hydroperoxide radicals. A ration of encapsulated oilcontaining bread contributes $60 \%$ of the recommended dietary intake of omega-3 fatty acids.

Keywords: enriched bread; chia oil; omega-3; technological quality; oil quality

\section{Introduction}

Current food trends show the strong interest of consumers in food that, as well as having greater nutritional value provides benefits to the physiological functions of the organism. There is a marked increase in the development of novel food products with functional properties, and baked goods are one of the categories that offer greater alternatives ${ }^{(1)}$. Given that the consumption of bakery products in Argentina is one of the highest in the world, the 
incorporation of essential nutrients in this foods group would have a significant impact on the quality of people's daily diet. It is important to highlight the advantages associated with this kind of product, such as low cost, ease of packaging and transport, long-term preservation and widespread consumption ${ }^{(2)}$.

A diet rich in polyunsaturated fatty acids decreases the risk of many diseases, especially cardiovascular, cancer and metabolic syndromes. The regular consumption is an effective way to reduce cholesterol and triglyceride levels in blood, and helps to regulate blood pressure ${ }^{(3)}$. Several studies have shown that omega- 6 and omega-3 fatty acids should not only be consumed in sufficient quantities, but also in a certain proportion between them. Simopoulos found that an omega-6/omega-3 ratio of at least 5:1 produces beneficial changes in asthmatic persons, and a ratio of $4: 1$ prevents up to $70 \%$ of cardiovascular disease. Studies show that Western diets have a ratio of from $10 / 1$ to $20-25 / 1$, indicating that they are deficient in omega-3 fatty acids ${ }^{(4)}$.

Chia has been studied principally because of its oil quality. The seed contains between 25 and $38 \%$ oil, of which the major constituents are triglycerides containing high amounts of omega-3 fatty acids $(61-70 \%)^{(5)}$. The International Society for the Study of Fatty Acids and Lipids (ISSFAL) recommends a dietary intake of $1 \mathrm{~g} /$ day of omega-3 fatty-acids ${ }^{(3)}$. Since most societies do not achieve these basic nutritional requirements due to regional, dietary and sociocultural preferences, supplementation with polyunsaturated fatty acids in commonly consumed products proves necessary ${ }^{(6)}$. Several studies on food enrichment can be founded in the literature including Indian yogurt ${ }^{(7)}$ or chocolate milk ${ }^{(8)}$ fortified with omega-3 fatty acids.

As these authors demonstrate, foods with large amounts of PUFAs have a positive impact on human health from the nutritional point of view; however, when these products are exposed to air, light and temperature, oxidation reactions occur that alter their chemical and organoleptic quality and decrease their shelf life. Microencapsulation of omega-3 and omega-6-rich oils can 
provide a protective effect against oil oxidation and thus their utilization as ingredients in baked goods presents a scientific and technological challenge. The change of the physical state from liquid oil to a dry and free-flowing powder it's a major advantage of the microencapsulation process for several industrial processes like mixing, storage, etc ${ }^{(9)}$.

Some examples of enriched breads can be found in the literature. Yep et al. developed a bread enriched with microencapsulated tuna oil and found that its consumption increases plasma docosahexaenoic acid and total omega-3 fatty acids in humans ${ }^{(10)}$. In another study, a commercial omega-3 concentrate containing EPA and DHA was microencapsulated and included in dough formulations. The addition of microencapsulated omega-3 affected most of the technological characteristics (specific volume, firmness, $\mathrm{L}^{*}$ and $\mathrm{C}^{*}$ ) and the sensory characteristics (appearance, aroma and overall acceptance) of white pan breads but this work did not study the oxidative stability of microencapsulated fatty acids ${ }^{(11)}$. Other examples of omega3 bread enrichment include the addition of concentrates, flax seed oil ${ }^{(12,13)}$, tuna oil ${ }^{(10)}$, fish oil ${ }^{(14)}$; however, the utilization of chia oil as a PUFA source in enriched breads has not previously been described.

A previous study described the preparation and characterization of chia oil microcapsules with soy protein isolate (SPI) and maltodextrin (MD) in different proportions as wall materials, obtained by spray-drying and freeze-drying. The retention and encapsulation efficiency as well as the oxidative stability of the encapsulated oils with respect to unencapsulated chia oils were studied. It was concluded that freeze-drying microencapsulation with SPI as wall material showed the best results in terms of oil quality. The microencapsulation technology improved the oil's oxidative stability. Encapsulated chia oil showed induction times 2 and 3 times longer than unencapsulated chia oil. Moreover, an increase of $30-48 \%$ in the shelf life of chia oil was determined by storage studies in which the hydroperoxide values (HPV) of encapsulated chia 
oils were lower than the Codex recommended limit (15 meq $/ \mathrm{kg}$ oil) in samples stored up to 90 days ${ }^{(15)}$.

The aim of this study was to analyze the effects of chia (unencapsulated) oil and microencapsulated chia oil on bread quality and on oil quality after baking and bread storage. In addition, the evaluation of the oil release was determined for the microcapsules in in-vitro gastric and intestinal conditions.

\section{Experimental}

\section{Materials}

The following ingredients were used: wheat flour obtained from a local distributor (Molinos Boero, Argentina), compressed yeast (Calsa, Argentina), salt (Dos Anclas, Argentina), sugar (Ledesma, Argentina), sodium stearoyl lactylate (ALPHA C.I.S.A., Argentina) and \pm -amylase (Novozymes Fungamyl 4000 BG).

\section{Preparation of chia oil-containing microcapsules}

Chia oil were obtained from seeds that were hydrated to obtain $10 \%(\mathrm{w} / \mathrm{w})$ moisture content. Oil extraction was carried out using a screw press (Komet Model CA $59 \mathrm{G}$, Germany) at $30^{\circ} \mathrm{C}$ with a $6 \mathrm{~mm}$ restriction die and a screw speed of $20 \mathrm{rpm}$. Chia oil-containing microcapsules using SPI as wall material were prepared as it was described in a previous work ${ }^{(15)}$. Briefly, SPI dispersion $(8 \%, \mathrm{w} / \mathrm{v}$ in dry basis) was prepared in distilled water and stirred at room temperature for $1 \mathrm{~h}$. This dispersion was adjusted to $\mathrm{pH} 7.0$ with $0.2 \mathrm{M} \mathrm{NaOH}$ and kept overnight at $4{ }^{\circ} \mathrm{C}$ for complete protein hydration. Chia oil was incorporated dropwise into the dispersions at a 2:1 ratio (wall materials : oil) for $15 \mathrm{~min}$ at $18000 \mathrm{rpm}$, using an Ultraturrax 
homogenizer (IKA T18, Germany). The resulting emulsions $\left(200 \mathrm{~mL}\right.$ lots) were stored at $4{ }^{\circ} \mathrm{C}$ before starting the drying process. In order to eliminate water, the emulsions were freeze-dryed in a laboratory bench-top freeze-dryer (Rificor L-T8, Argentina) operated with a condenser at $50^{\circ} \mathrm{C}$ and a vacuum of 0.1 mbar during $36 \mathrm{~h}^{(15)}$.

\section{In-vitro gastric and intestinal digestion of microcapsules}

In order to study the amount of chia available oil for intestine absorption, an in-vitro digestion was carried out through gastric and intestinal steps following a reported procedure with some modifications ${ }^{(16)}$. Two grams of chia oil microcapsules prepared as was described in previous report ${ }^{(15)}$ were exposed to $30 \mathrm{~mL}$ of simulated gastric fluid (SGF) containing sodium chloride and pepsin at $\mathrm{pH} 1.2 \mathrm{in}$ an orbital shaking bath for $2 \mathrm{~h}$ at $37^{\circ} \mathrm{C}$. After that, $\mathrm{pH}$ was adjusted to 6.8 using a $\mathrm{NaOH}$ solution and $30 \mathrm{~mL}$ of a simulated intestinal fluid (SIF) containing pancreatin in PBS buffer at $\mathrm{pH} 6.8$ was added and mixed for $2 \mathrm{~h}$ at $37^{\circ} \mathrm{C}$. SGF and SIF were obtained according the USP method ${ }^{(17)}$. To determine the amount of available oil after digestion (\%AO), the lipid compounds were extracted with three portions of $30 \mathrm{~mL}$ of $\mathrm{n}$-hexane. Then the solvent was completely evaporated and the remaining oil was weighed $\left(\mathrm{w}_{\mathrm{f}}\right)$ and compared to the initial amount of oil added in the MC preparations $\left(\mathrm{w}_{\mathrm{i}}\right)$. The \%AO was calculated as Equation 3.

$\% \mathrm{AO}=\left(\mathrm{w}_{\mathrm{f}} / \mathrm{w}_{\mathrm{i}} \times 100\right) \quad($ Eq. 3$)$

\section{Bread-making procedure}

The dough base formulation used in this study comprised $100 \mathrm{~g}$ of wheat flour, $3 \mathrm{~g}$ of compressed yeast, $1 \mathrm{~g}$ of salt, $2.5 \mathrm{~g}$ of sugar, $0.3 \mathrm{~g}$ of sodium stearoyl lactylate, $0.02 \mathrm{~g}$ of \pm amylase and $56.8 \mathrm{~g}$ of water. The ingredients were mixed in a mixer (MPZ, Argentina). Yeast, salt and sugar were separately dissolved in water and the remaining ingredients were added as 
solids. Chia oil microcapsules (MC) (5.2 g) or bulk chia oil (1.7 g) were added to the dough to produce MC-containing bread (Bread+MC) or oil-containing bread (Bread+oil), respectively. Bread samples without chia oil or MC aggregates were considered as control breads. The resulting dough (approximately at $23^{\circ} \mathrm{C}$ ) was covered with plastic film and allowed to rest for $10 \mathrm{~min}$ at room temperature. Dough was divided into $165 \mathrm{~g}$ pieces, molded into a loaf shape (Braesi MB 350, Brazil), panned (dimensions $15 \cdot 8 \cdot 6 \mathrm{~cm}$ ) and put in a fermentation cabinet (Pauna, Argentina) at $30^{\circ} \mathrm{C}$ and $96 \% \mathrm{RH}$ for $60 \mathrm{~min}$, and baked at $220^{\circ} \mathrm{C}$ for $15 \mathrm{~min}$ in an airforced oven (Pauna, Argentina). Temperature in the core of the dough during baking was recorded using a TES-1307 data logger (Electrical Electronic Corp., Taiwan). Temperature on the crust immediately after baking was recorded with a digital infrared thermometer (Fluke62Max, USA). The loaves were photographed with a digital camera (Sony, Japan) and then were stored up to 14 days in sealed plastic bags. Samples were previously sprayed with a solution of potassium sorbate to prevent mold growth on the surface of the loaves.

\section{Moisture content}

Bread moisture was measured at $2 \mathrm{~h}$ after baking (day 0 of storage) and at 7 and 14 days of storage with an analytical instrument (OHAUS MB45, USA). The set-up of the determination was the following: $2 \mathrm{~g}$ of crumb taken from the loaf center was heated to $130^{\circ} \mathrm{C}$ and the weight was recorded until a constant value. The moisture content was calculated as the difference between the initial weight and the dry weight and this was measured in triplicate.

\section{Specific loaf volume (SLV)}

The volume of each loaf was determined by rapeseed displacement. The SLV was obtained by dividing bread volume/bread weight according to the AACC 10-05 method ${ }^{(18)}$. These tests were 
performed $2 \mathrm{~h}$ after baking. Three measurements of each breadmaking replication were performed and three lots were evaluated.

\section{Crust color determination}

Bread color was determined with a Konica-Minolta CM600d spectro-photometer, 8-mm measurement aperture, D65 illuminant, $10^{\circ}$ angle of observer, CIE, according to Approved Methods (19). Crust color was measured from the top position of each bread loaf. At least three readings were taken from each loaf and at least four loaves from each test point and recorded as CIE-LAB, L* (lightness), a* (redness-greenness), and b* (yellowness-blueness) values.

Chroma value $\left(C^{*}\right)$ refers to the CIELCh color system ${ }^{(19)}$ and was calculated as Equation 1: $\mathrm{C}^{*}=\left(\mathrm{a}^{* 2}+\mathrm{b}^{* 2}\right)^{1 / 2}$ (Eq. 1)

\section{Crumb structure characterization}

Bread samples were cut in half and $15 \mathrm{~cm}$-thick slices were obtained from the central regions. Digital images of the loaves were obtained from slices using a scanner (HP Scanjet G3010, USA), with 600 dpi resolution. Images were analyzed using ImageJ Software 1.41o (National Institutes of Health, USA). Image binarization was carried out according to Ribotta, et al., 2001 ${ }^{(20)}$. Cell average area $\left(\mathrm{mm}^{2}\right)$ and percentage of area occupied by air cells in relation to the total area $(\% \mathrm{AC})$ were determined. The ratio of large cells $\left(4.00<x<10.00 \mathrm{~mm}^{2}\right)$ to small cells $\left(0.15<x<4.00 \mathrm{~mm}^{2}\right)$ was calculated and was used as a measure of crumb uniformity. Five slices from three different loaves were analyzed in each breadmaking batch.

\section{Crumb morphology determination}


The crumb morphology was studied using a confocal laser scanning fluorescence microscope (LSM5 Pascal Zeiss, Germany). To visualize the oil distribution in the crumb microstructure, a staining technique was used. The fat phase was stained by adding Nile Red (Sigma-Aldrich, USA) ( $1 \mathrm{~g} / \mathrm{kg}$ fat basis) with excitation with a $488 \mathrm{~nm}$ argon-ion laser and detection through a $515 / 30$ filter.

\section{Crumb texture profile analysis}

Texture profile analysis (TPA) was performed using an Instrom Universal Testing Machine model 3342 equipped with a $500 \mathrm{~N}$ load cell. A cylinder probe of $2.5 \mathrm{~cm}$ diameter was attached to a moving cross-head. The loaves were cut and two slices $(2.5 \mathrm{~cm}$ thick $)$ were subjected to a double cycle of compression under the following conditions: $1 \mathrm{~mm} / \mathrm{s}$ cross-head speed and $40 \%$ maximum deformation. Bread crumb hardness, chewiness, springiness and cohesiveness were determined. Hardness is defined as the force required to compress the bread slice to $40 \%$ of its initial thickness ${ }^{(21)}$. Chewiness (hardness $\times$ cohesiveness $\times$ springiness) is defined as the force required to disintegrate the solid food until it is swallowed ${ }^{(21)}$. Four slices from two different loaves were analyzed in each breadmaking batch.

\section{Hydroperoxide value determination (HPV).}

Hydroperoxide values (HPV) were determined of the oil extracted from the control bread, Bread + oil and Bread $+\mathrm{MC}$ samples stored for 0,7 and 14 days. These measurements were carried out by iodometric titration, following an AOCS methodology (22) with some modifications. Oil samples were extracted from Bread $+\mathrm{MC}$, Bread $+\mathrm{oil}$ and control bread samples by inmersing the bread crumb in hexane for $24 \mathrm{~h}$ at room temperature and then evaporating the solvent in vacuum at $36^{\circ} \mathrm{C}$. Then, $0.20 \pm 0.01 \mathrm{~g}$ of the extracted oil was placed 
in $10 \mathrm{~mL}$ vials, and $3 \mathrm{~mL}$ of acetic acid: chloroform $(3: 2 \% \mathrm{v} / \mathrm{v})$ was added and stirred vigorously until complete dissolution was achieved. Subsequently, $0.5 \mathrm{~mL}$ of saturated potassium iodide solutionwas added and the solution was kept in the dark for $1 \mathrm{~min}$. The reaction was stopped by the addition of $3 \mathrm{~mL}$ of distilled water, and $0.5 \mathrm{~mL}$ of starch solution $(1 \%, \mathrm{w} / \mathrm{v})$ was added as an indicator. Finally, solutions were titrated with $5.10^{-4} \mathrm{M} \mathrm{Na}_{2} \mathrm{SO}_{3}$ until the brown color disappeared.

This assay was performed in duplicate for each sample. The calculation of HPV was carried out using Equation 2 which is expressed in milliequivalents of oxygen $/ \mathrm{kg}$ oil.

$\mathrm{HPV}=(\mathrm{S}-\mathrm{B}) \times \mathrm{N} \times 1000 / \mathrm{w}$

where $\mathrm{S}$ represents the volume in $\mathrm{mL}$ of the sodiumthiosulfate solution consumed by the sample, and $\mathrm{B}$ is the volume consumed by the blank. $\mathrm{N}$ is the normality of sodium thiosulfate solution, and w represents the weight of oil expressed in grams. Analyses were made in triplicate.

\section{Fatty acid composition}

Two different experiments were carried out. First, oil samples were extracted from Bread $+\mathrm{MC}$, Bread+oil and control bread samples by inmersing the bread crumb in hexane for $24 \mathrm{~h}$ at room temperature and then evaporating the solvent in vacuum at $36^{\circ} \mathrm{C}$.

Second, in order to determine the effect of the temperature and matrix (dough to crumb during baking) on oil quality parameters, aluminium cartridges with $1 \mathrm{~g}$ of $\mathrm{MC}$ were produced andput inside the dough piece. A thermocouple was placed inside the dough piece (near the aluminum cartridges) to sense the temperature during baking. When the dough pieces reached the desired temperature $\left(50,70\right.$ and $\left.95^{\circ} \mathrm{C}\right)$, they were removed from the oven and cooled at room temperature for further analysis. 
Oil samples were extracted from microcapsules by inmersing them in hexane for $24 \mathrm{~h}$ at room temperature and then evaporating the solvent in vacuum at $36^{\circ} \mathrm{C}$.

The fatty acid composition of oil samples was analyzed in triplicate with 3 different baking batches according to the procedure employed by Martínez et al. with minor modifications ${ }^{(23)}$. Briefly, oil samples $(0.2 \mathrm{~g})$ were subjected to alkaline saponification (reflux, $\mathrm{KOH}$ in methanol). The fatty acid methyl esters (FAMEs) were obtained by reflux $\left(\mathrm{NH}_{4} \mathrm{Cl}\right.$ and $\mathrm{H}_{2} \mathrm{SO}_{4}$ in methanol) and analyzed by gas chromatography (Perkin Elmer, Shelton, USA) using a fused-silica capillary column (ZEBRON ZB-WAX, $30 \mathrm{~m}, 0.25 \mathrm{~nm}$ ID); carrier gas $\mathrm{N}_{2}$ at $1 \mathrm{~mL} / \mathrm{min}$; column temperature programmed from $180^{\circ} \mathrm{C}(5 \mathrm{~min})$ to $210^{\circ} \mathrm{C}$ at $2^{\circ} \mathrm{C} / \mathrm{min}$; injector and detector temperatures $250^{\circ} \mathrm{C}$; detector FID. The identification of FAMEs was carried out by comparing their retention times with those of reference compounds (Sigma-Aldrich, USA). Quantification of each fatty acid analyzed was made by using the internal standard Henicosanoic acid (SigmaAldrich, USA).

\section{Sensorial determination}

The 40 semi-trained assessors were from Cordoba (Argentina) and were recruited according to the following criteria: ages between 25 and 55 years old; people without food allergies; nonsmokers; people who consume bread regularly; people interesting in participating ${ }^{(24)}$. Bread samples cut in slices were evaluated. The bread samples were compared to a well-known bread product (control sample) and a 9-point scale was used to indicate degrees of disliking to liking of a particular attribute with respect to the control sample. The control sample was in the middle of the scale (5 points, "Just right") ${ }^{(25)}$. A slice of each bread was served in a plastic container, coded with a random three-digit number. Water was used for rinsing the palate between samples. The test was carried out 24 hours after baking trials. Five attributes were 
analyzed: general aspect, odor, texture, flavor and general acceptability. Sensory instructions are detailed in Appendix B and the template provided to assessors for sensory attributes evaluation is showed in Appendix C. In order to know the preference order of the bread samples including the control, a ranking test $(1=$ most accepted sample and $3=$ least accepted sample $)$ was also performed.

\section{Statistical analysis}

Data for each test were statistically analyzed. Analysis of variance (ANOVA) was used to evaluate the significance in the difference between means. Tukey's test was used for comparing mean values in all determination except for sensory analysis where a LSD Fisher's test was performed. Differences between means were considered significant when $\mathrm{P}<0.05$. A multivariate analysis (Hotelling's test) was performed to evaluate sensorial determinations.

\section{Results and discussion}

Chia oil-containing microcapsules using SPI as wall material were prepared and characterized as is showed in a previous work ${ }^{(15)}$. HPV values were lower than the limit of acceptance expressed by Codex (15 meq/kg oil) in samples stored up to 90 days. These microcapsules contain $30 \mathrm{~g} \mathrm{~kg}^{-1}$ of moisture and $0.31 \pm 0.02 \mathrm{~g}$ of oil $/ \mathrm{g}$ of solid, of which $61.1 \pm 10.1 \%$ of that oil is encapsulated and the rest is in the surface of the microcapsule.

The digestibility of these microcapsules was measured to determine how much oil is available to be absorbed by the organism after ingestion and after passage through the gastrointestinal tract. For this, the microcapsules were treated with simulated gastric and intestinal fluids at 
$37^{\circ} \mathrm{C}$. Released oils were extracted and quantified gravimetrically. From this procedure, it was determined that $(94.83 \pm 2.57) \%$ of the oil originally contained in the microcapsules is released and available for absorption in the intestine after its passage through the gastrointestinal tract.

"In addition, the fatty acid profiles of oils extracted from microcapsules before and after digestion did not show significant differences (Table 4), suggesting that simulated gastrointestinal conditions do not alter the chemical characteristics of oil

Microcapsules and bulk oil were added as an ingredient in dough formulation to prepare omega3 enriched breads. Loaves were obtained containing encapsulated or nonencapsulated oil (Bread $+\mathrm{MC}$ and Bread+oil, respectively) and without oil (control bread). The crumb temperature was measured by introducing a sensor in the center of the dough piece. This instrument registered the internal temperature of dough during the entire baking process. These temperature values plotted as a function of time are shown in Appendix A.

A sigmoidal profile temperature was determined with no differences between samples, reaching an internal temperature of $(95.0 \pm 0.6){ }^{\circ} \mathrm{C}$ in the center of the crumb. In addition, temperature measured on the crust at the end of the baking process was $(154 \pm 2){ }^{\circ} \mathrm{C}$. After baking, the macroscopic aspect of the breads showed homogeneous colored surfaces and uniform crumb structures with no collapsed alveoli formation. Oil-containing bread showed the higher dimension ratio (height/width) $(0.84 \pm 0.06)$ while control bread and bread $+\mathrm{MC}$ showed $0.79 \pm 0.04$ and $0.78 \pm 0.03$ dimension ratio values, respectively (Figure 1).

\section{Figure 1.}

\section{Evaluation of the technological quality of breads}


To determine if the presence of MC or free oil affects bread quality, a series of properties of the product quality were measured.

Bread moisture was measured and results are shown in Table 1.

\section{Table 1}

While no significant differences were determined in relation to control, Bread+MC and Bread + oil samples, a statistically significant difference was observed with respect to storage time, as expected. The only case where a variation between samples was observed in the case of bread containing oil after 14 days of storage, where lower moisture was observed with respect to the other two samples. This result was expected since Bread+oil samples had the highest volume so a higher migration of water from the crumb to the crust is feasible because it has a larger proportional amount of crust with respect to the crumb ${ }^{(26)}$.

Crust color parameters are shown in Table 2 . Bread $+\mathrm{MC}$ samples were significantly darker than the control bread, while Bread + oil samples presented similar color parameters to the control bread. This effect was attributed to the presence of microcapsules located in the surface of the loaves. Microcapsules are composed mainly by soy proteins. It is suggested that these proteins produce an increase in the proportion of Maillard reactions with the polysaccharides present in the dough during baking and an increase of the crust browning.

In agreement with Cauvain ${ }^{(27)}$, the addition of unencapsulated oil significantly increased the specific volume and the area occupied by alveoli with respect to the total area, while this was not altered with the incorporation of MC (Table 2). The effect of adding oil to bread formulations has been described by Pareyt et al ${ }^{(28)}$. Despite bread formulations generally 
containing low levels $(<5 \%)$ of added oil or fat, these affects both processing and sensory quality. According to the review made by these authors, fat plasticizes and lubricates dough (in particular, the gluten polymers) and increases dough rise, oven spring and loaf volume. Shortening also affects crumb structure, tenderizes the baked bread and extends the shelf life or keeping quality.

It is known that variations in the specific volume of loaves bring about changes in the alveolate of the loaves, since the increase in the amount of air contained inside the crumb increases loaf volume. This was corroborated by determining the size of cells of each loaf and the percentage of the area occupied by cells, through bread slice imaging analysis.

\section{Table 2.}

It can be observed that Bread+oil sample had the highest values of percentage of area occupied by air cells in relation to the total area, specific volume and the cell size. Bread $+\mathrm{MC}$ showed lower cell average area than Bread+oil, leading to an increase in crumb uniformity (greater rate of smaller cells than cells larger than $4 \mathrm{~mm}^{2}$ ).

Bread texture was studied by TPA analysis. Properties such as hardness, chewiness, springiness and cohesiveness were determined to evaluate the effect on bread texture produced by the addition of encapsulated and unencapsulated chia oil. The results can be seen in figure 2 .

\section{Figure 2.}

The presence of unencapsulated oil affected the firmness of the loaves and therefore the chewiness, producing softer loaves, while it did not produce significant variations in elasticity 
and cohesiveness. In contrast, the addition of microencapsulated oil did not modify the texture of the loaves compared to control bread.

The effect of storage time showed, as expected, an increase in hardness and chewiness and a decrease in elasticity and cohesiveness over time. At 7 and 14 days of storage, the effect produced by the addition of unencapsulated oil was more marked, since the firmness and chewiness had a lower rate of increase compared to control bread and Bread $+\mathrm{MC}$. The results suggested that the addition of unencapsulated oil improved the texture properties of the loaves during the whole storage time. This effect is well known and described in literature ${ }^{(27)}$. On the other hand, the addition of microencapsulated oil did not modify the texture properties of loaves, which is as expected since the purpose of microencapsulation is the enrichment of bread with healthy components without affecting their technological quality. A similar behavior was reported in the literature for encapsulated fish oil using soy proteins as wall material ${ }^{(14)}$. In contrast, for breads containing flax seed oil with high amylose corn starch as wall material, a linear rise in hardness and chewiness values was reported with a continued increase of microcapsule content. In addition, a decrease in SLV and number of alveoli and size were reported. The authors attribute this effect to a dilution in gluten content ${ }^{(12)}$.

The microscopic morphology and the presence and distribution of MC and free oil in crumbs were also studied by confocal microscopy with fluorescence using nile red as fluorescent staining of fatty compounds. The confocal images obtained can be seen in Figure 3.

\section{Figure 3.}

The confocal micrographs showed microencapsulated oil as droplets homogeneously dispersed in the matrix (Figure 3A). In a previous work, microcapsules obtained by freeze-drying were 
described as agglomerates or scales of soy proteins including oil droplets ${ }^{(15)}$.Hence, Bread+MC showed oil droplets of different sizes and a non-homogeneous distribution, which can be associated to the presence of these agglomerates or scales with high content of oil droplets (arrow 1 in Figure 3). As expected, in areas where these structures are not present, no oil drops were observed.

On the other hand, Bread+oil samples showed a more homogeneous distribution of oil droplets throughout the crumb and the oil droplets were smaller. The dark areas of Bread+oil micrographs correspond to areas where the alveoli are located (arrow 2 in Figure 3). Figure 3 shows only one image for each sample, but the effects explained were representative of all captured images.

\section{Evaluation of the chemical quality of the oil}

The measurement of oil hydroperoxide values (HPV) did not show evidence of oxidation in bread containing microencapsulated oil. In fact, no differences were founded between control oil and oil extracted from Bread $+\mathrm{MC}$ samples after baking. In contrast, oil extracted from Bread + oil samples presented a higher HPV values than oil extracted from Bread + MC samples during the storage period. This clearly shows the protective effect of the microcapsule wall against bread processing conditions. It was also observed that the microencapsulation process did not affect the oil quality, since there is no increase in the HPV values of MC sample compared to control oil. Analyzing the influence of storage time in oil-containing breads, the protective effect provided by the microcapsule walls was reflected for up to 14 days, since the HPV increased at a higher rate for unencapsulated than for encapsulated oil.

\section{Table 4}


The results obtained from the measurement of the fatty acid profiles showed a decrease of approximately $16 \%$ and $13 \%$ of \pm -linolenic acid (omega-3) in the Bread + oil and Bread $+\mathrm{MC}$ samples compare to control oil (Table 4), which suggested that the baking process minimally affected the structure of this molecule in the matrix, and that the microencapsulation process did not have the expected protective effect on this essential fatty acid.

As regards the expected protective effect on the oil's oxidative stability, although microencapsulation could not prevent the reduction in omega-3content, it is important to note that it did prevent lipid oxidation, avoiding the generation of hydroperoxides responsible for the formation of secondary products that are toxic to human health. In addition, other reports showed higher reductions in the amounts of \pm -linolenic acid produced by the bread baking. Gallardo et al. ${ }^{(13)}$ reported a reduction of $67 \%$ in the initial \pm -linolenic acid present in gum arabic microcapsules added to bread preparation.

To estimate the dependence of \pm -linolenic acid degradation with the temperature, fatty acid profiles were determined for oils extracted from microcapsules incorporated in the center of the dough but separated from the bread matrix, in a container made of aluminum foil. Loaves containing $\mathrm{MC}$ in aluminum foil were removed from the oven when the internal temperature reached 50,70 and $95^{\circ} \mathrm{C} .95^{\circ} \mathrm{C}$ is the maximum internal temperature reached in baking the Bread + MC, Bread + oil and Control bread samples.

Table 4 shows a small decrease of \pm -linolenic acid and an increase in the other fatty acids with 18 carbon atoms (stearic, oleic and linoleic acid) as temperature increased. It can also be observed that the decrease obtained for samples removed at the end of the baking process $\left(95^{\circ} \mathrm{C}\right.$ sample) was lower than those observed for Bread $+\mathrm{MC}$. This difference can be attributed to the fact that, in the samples with MC inside the cartridge, these are placed just in the middle of the bread crumb, but in the Bread $+\mathrm{MC}$ sample, microcapsules were distributed in the whole crumb, 
which means that some of them were closer or were part of the crust, with a higher temperature than that of the microcapsules placed in the middle of the crumb.

To find sensorial differences or similarities between samples and the control sample, a sensory analysis was carried out with 40 semi-trained assessors,evaluating five attributes: general aspect, odor, texture, flavor and general acceptability.

From the results that can be seen in Table 5, a multivariate analysis of these attributes was performed, which determined that there were no significant differences between the samples or with the control sample ( $>0.05)$. However, the individual statistical analysis of each attribute shows that odor and texture present significant differences between the samples respect to the control. It can also be seen that both samples present values between 5 and 7 in all attributes, which means that both breads with chia oil (encapsulated and unencapsulated) had better sensorial properties and general acceptability than the control bread. In addition, no differences were observed in the preference of Bread $+\mathrm{MC}$, Bread + oil and Control samples in the assessor's answers.

\section{Table 5}

In addition, after the sensory evaluation was completed, the assessors were told which the sample that contained microencapsulated chia oil was and they were asked about if they would consume it (Appendix D). 95\% stated that they would consume the enriched bread.

\section{Conclusions}


This study examined the effect of adding microencapsulated chia oil as an ingredient in the preparation of traditional breads, and determined important parameters that describe the technological quality of breads and the chemical quality of oils.

The addition of encapsulated chia oil did not alter the technological quality of breads, showed a protective effect against oil oxidation and prevented the formation of hydroperoxide radicals, leading to a safer product. On the other hand, a partial reduction of \pm -linolenic acid could not be prevented but represented a small loss. Nevertheless, Bread+MC samples were obtained containing $10.45 \mathrm{mg}$ of \pm -linolenic acid per gram of bread. Sensory assessors generally evaluated bread containing chia oil as better than bread without oil. Moreover, $95 \%$ of the assessors affirmed that they would consume the bread containing microencapsulated chia oil.

Considering the \pm -linolenic acid quantification, and the amount of available oil after simulated gastrointestinal digestion, it could be inferred that a ration of MC-containing bread (4 slices of 2 $\mathrm{cm}$ and $15 \mathrm{~g}$ each) contribute $60 \%$ of the recommended dietary intake of omega-3 fatty acids (approximately $627 \mathrm{mg}$ of \pm -linolenic acid per daily ration of bread). The development of such enriched products represents a contribution to health and the quality of human life.

\section{Acknowledgments}

The authors acknowledge financial support from CONICET (PIP-11220120100184), Fund for Scientific Research and Technology (FONCyT, BID PICT 2014-2283) and SECyT-UNC (05/M287) and thank Joss Heywood, native speaker, for revision of the manuscript.

\section{References}

1. Olagnero G, Abad A, Bendersky S, Genevois C, Granzella L, Montonati M,. Alimentos funcionales: fibra, prebióticos,probióticos y simbióticos. DIAETA 25: 20-33 (2007). 
2. Ribotta PD, Perez G, Añón MC, León AE,. Optimization of additive combination for improved soy-wheat bread quality. Food Bioprocess Technol 3: 395-405 (2010).

3. Hermida LG, Gallardo G,. Food Applications of Microencapsulated Omega-3 Oils. Elsevier Inc.; Vol. 14, Microencapsulation and Microspheres for Food Applications. 14: 2015. 271-299 p.

4. Simopoulos AP,. Evolutionary Aspects of Diet: The Omega-6 / Omega-3 Ratio and the Brain. Mol Neurobiol 44: 203-15 (2011).

5. Martínez ML, Marín MA, Salgado-Fallerc CM, Revol J, Penci MC, Ribotta PD,. Chia (Salvia Hispanica 1.) Oil extraction: study of processing parameters. LWT - Food Sci Technol 47: 78-82 (2012).

6. Ganesan B, Brothersen C, McMahon DJ,. Fortification of foods with omega-3 polyunsaturated fatty acids. Crit Rev Food Sci Nutr 54: 98-114 (2014).

7. Goyal A, Sharma V, Sihag MK, Singh AK, Arora S, Sabikhi L,. Fortification of dahi (Indian yoghurt) with omega-3 fatty acids using microencapsulated flaxseed oil microcapsules. J Food Sci Technol [Internet] 53: 2422-33 (2016).

8. Morato PN, Rodrigues JB, Moura CS, e Silva FGD, Esmerino EA, Cruz AG, et al.,. Omega-3 enriched chocolate milk: A functional drink to improve health during exhaustive exercise. J Funct Foods [Internet] 14: 676-83 (2015).

9. Barbosa-Cánovas G, Ortega-Rivas E, Juliano P, Yan H,. Food Powders. Kluwer Academic / Plenum Publishers; 2005.

10. Yep YL, Li D, Mann NJ, Bode O, Sinclair AJ,. Bread enriched with microencapsulated tuna oil increases plasma docosahexaenoic acid and total omega-3 fatty acids in humans. 11: 285-91 (2002). 
11. Costa de Conto L, Porto Oliveira RS, Pereira Martin LG, Chang YK, Steel CJ,. Effects of the addition of microencapsulated omega-3 and rosemary extract on the technological and sensory quality of white pan bread. LWT - Food Sci Technol 45: 103-9 (2012).

12. Gökmen V, Mogol BA, Lumaga RB, Fogliano V, Kaplun Z, Shimoni E,. Development of functional bread containing nanoencapsulated omega-3 fatty acids. J Food Eng [Internet] 105: 585-91 (2011).

13. Gallardo G, Guida L, Martinez V, López MC, Bernhardt D, Blasco R, et al.,. Microencapsulation of linseed oil by spray drying for functional food application. Food Res Int [Internet] 52: 473-82 (2013).

14. Davidov-Pardo G, Roccia P, Salgado D, León AE, Pedroza-Islas R,. Utilization of different wall materials to microencapsulate fish oil. Evaluation of its behavior in breas products. Am J Food Technol 3: 384-93 (2008).

15. González A, Martínez ML, Paredes AJ, León AE, Ribotta PD,. Study of the preparation process and variation of wall components in chia (Salvia hispanica L.) oil microencapsulation. Powder Technol 301: 868-75 (2016).

16. Goyal A, Sharma V, Sihag MK, Tomar SK, Arora S, Sabikhi L, et al.,. Development and physico-chemical characterization of microencapsulated flaxseed oil powder: A functional ingredient for omega-3 fortification. Powder Technol 286: 527-37 (2015).

17. Pharmacopeia,. National formulatory (USP 24 NF 19). MD, US: Rockville. 2000.

18. American Association of Cereal Chemists (AACC),. Approved methods of the AACC. Methods, St. Paul, USA: American Association of Cereal Chemists. 1995.

19. Minolta Camera Co.,. Precise color comunication. Osaka, Japan: Ramsey; Minolta Communication. 1993. 
20. Ribotta PD, Pérez GT, Añón MC, León AE,. Relationships between Different Hydration Properties of Commercial and Laboratory Soybean Isolates. Scan Electron Microsc 0: $4852-8(2001)$.

21. Steffolani E, Ribotta PD, Perez GT, León AE,. Combinations of glucose oxidase , a amylase and xylanase affect dough properties and bread quality. Int J Food Sci Technol 47: 525-34 (2012).

22. AOCS,. Official Methods and Recommended Practices of the American Oil Chemists' Society, fifth ed. AOCS Press, Champaign, Il, USA. 2009.

23. Martínez ML, Mattea MA, Maestri DM,. Varietal and crop year effects on lipid composition of walnut (Juglans regia L.) genotypes. Journal of the. Am Oil Chem Soc 83: 791-6 (2006).

24. Plemmons LE, Resurreccion AVA,. A warm-up sample improves reliability of responses in descriptive analysis. $J$ Sens Stud 13: 359-376 (1998).

25. Meilgaard M, Civille GV, Carr BT,. Sensory evaluation techniques. Boca Raton, Florida, USA: CRC Press; 1991.

26. Ribotta PD, Le Bail A,. Thermo-physical assessment of bread during staling. LWT Food Sci Technol 40: 879-84 (2007).

27. Cauvain SP,. Breadmaking, Improving quality. Second edd. New Delhi, India: Woodhead Publishing; 2012.

28. Pareyt B, Finnie SM, Putseys JA, Delcour JA,. Lipids in bread making: Sources, interactions, and impact on bread quality. J Cereal Sci 54: 266-79 (2011). 


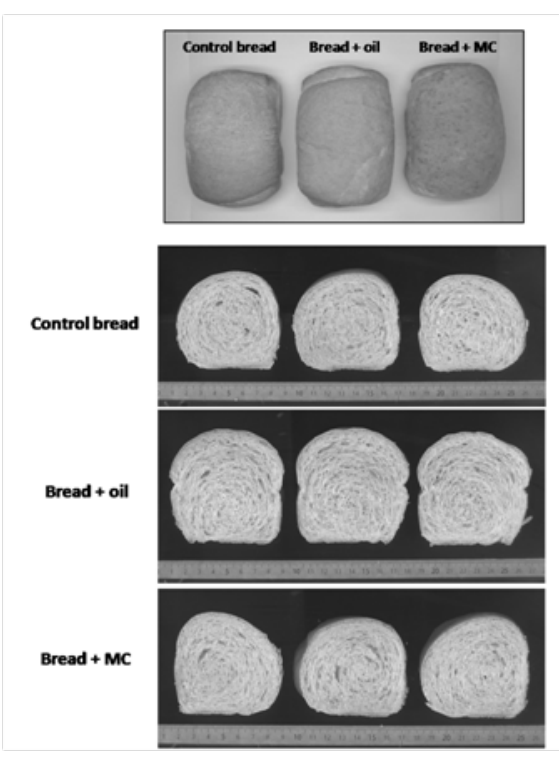

Figure 1 b\&w.tif

This article is protected by copyright. All rights reserved. 

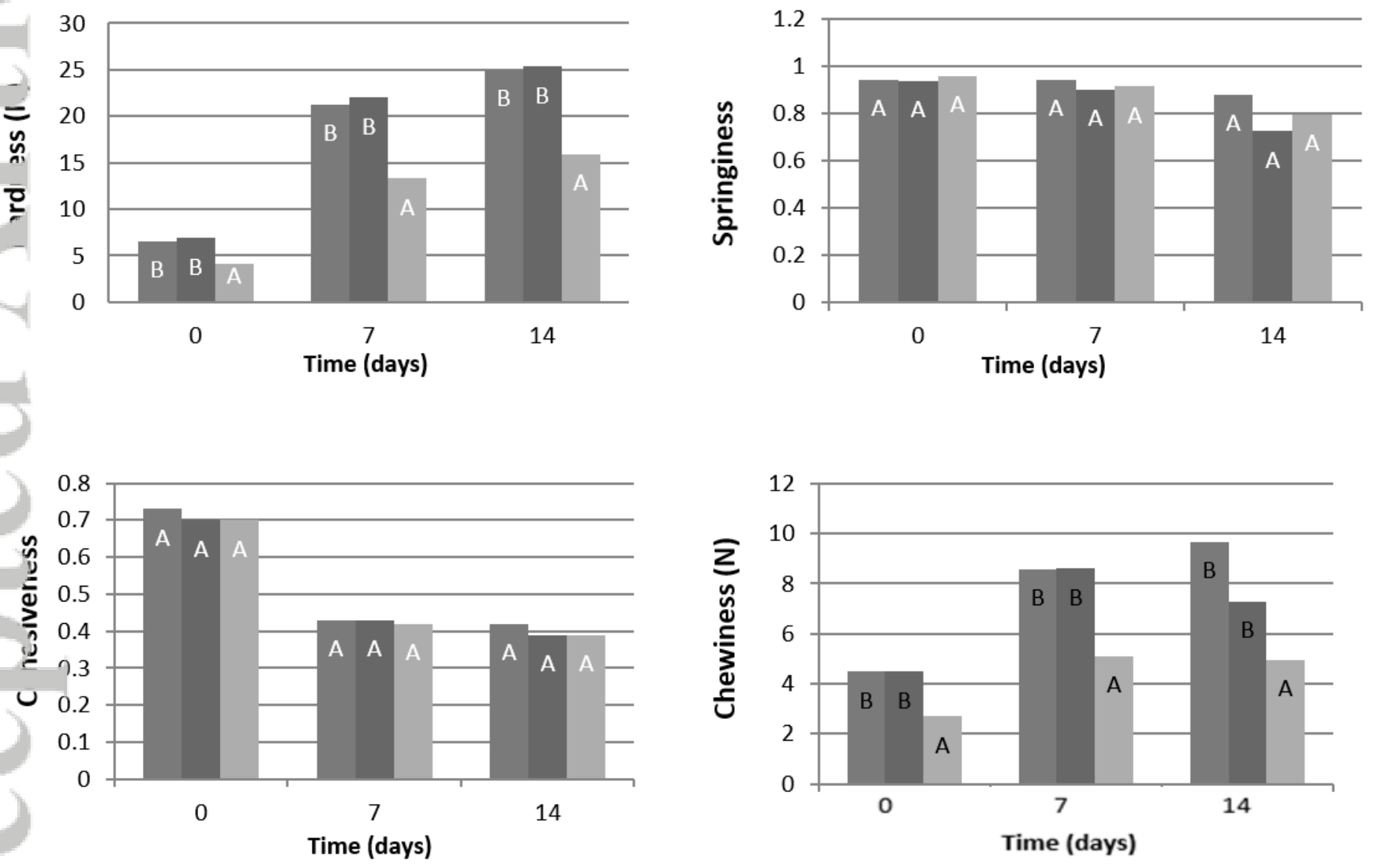

Control bread Bread + MC $\quad$ Bread + oil

Figure 2 b\&w.tif 
B

Figure 3 color.tif 
Table 1. Moisture content determination $\left(\mathrm{g} \mathrm{kg}^{-1}\right)$ of stored breads at 0,7 and 14 days.

\begin{tabular}{cccc}
\hline Bread type & Day 0 & Day 7 & Day 14 \\
\hline Control bread & $419 \pm 4^{\mathrm{A}}$ & $393 \pm 5^{\mathrm{A}}$ & $373 \pm 6^{\mathrm{B}}$ \\
Bread + MC & $421 \pm 3^{\mathrm{A}}$ & $396 \pm 8^{\mathrm{A}}$ & $379 \pm 6^{\mathrm{B}}$ \\
Bread + oil & $415 \pm 9^{\mathrm{A}}$ & $391 \pm 3^{\mathrm{A}}$ & $359 \pm 8^{\mathrm{A}}$ \\
\hline Any two means in the same column followed by the same letter are not significantly (Pe 0.05) different according to the Tukey test.
\end{tabular}


Table 2. Color parameters of loaf crumb surface, specific loaf volume (SLV) and structural parameters of crumb. \%AC: percentage of area occupied by cells with respect to total area.

\begin{tabular}{cccc}
\hline & Control bread & Bread+MC & Bread+oil \\
\hline $\mathbf{L}^{*}$ & $62.40 \pm 3.62^{\mathrm{B}}$ & $60.05 \pm 2.33^{\mathrm{A}}$ & $61.04 \pm 2.08^{\mathrm{AB}}$ \\
$\mathbf{a}^{*}$ & $11.48 \pm 1.09^{\mathrm{A}}$ & $11.81 \pm 0.63^{\mathrm{A}}$ & $11.79 \pm 0.67^{\mathrm{A}}$ \\
$\mathbf{b}^{*}$ & $30.14 \pm 0.76^{\mathrm{B}}$ & $28.60 \pm 0.71^{\mathrm{A}}$ & $29.78 \pm 0.96^{\mathrm{B}}$ \\
$\mathbf{C}^{*}$ & $32.27 \pm 0.91^{\mathrm{B}}$ & $30.95 \pm 0.79^{\mathrm{B}}$ & $32.03 \pm 1.09^{\mathrm{B}}$ \\
$\mathbf{S L V}\left(\mathbf{c m}^{\mathbf{3}} / \mathbf{g}\right)$ & $3.549 \pm 0.511^{\mathrm{A}}$ & $3.389 \pm 0.105^{\mathrm{A}}$ & $4.083 \pm 0.192^{\mathrm{B}}$ \\
\%AC (\%) & $39.0 \pm 2.9^{\mathrm{A}}$ & $37.2 \pm 1.0^{\mathrm{A}}$ & $41.4 \pm 1.0^{\mathrm{B}}$ \\
Cell average area (cm & $0.018 \pm 0.003^{\mathrm{AB}}$ & $0.016 \pm 0.001^{\mathrm{A}}$ & $0.019 \pm 0.002^{\mathrm{B}}$ \\
Crumb Uniformity & $8.73 \pm 1.05^{\mathrm{A}}$ & $11.71 \pm 1.68^{\mathrm{B}}$ & $8.34 \pm 1.38^{\mathrm{A}}$ \\
\hline
\end{tabular}

Any two means in the same raw followed by the same letter are not significantly ( $\mathrm{P}$ e 0.05$)$ different according to the Tukey test 
Table 3. Hydroperoxide values (meq $\mathrm{kg} \mathrm{oil}^{-1}$ ) of the oils extracted from breads, of microcapsules before being added to the bread preparation (MC) and control oil used without encapsulation.

\begin{tabular}{cccc}
\hline & Day 0 & Day 7 & Day 14 \\
\hline Control bread & $0.36 \pm 0.08^{\mathrm{A}}$ & $0.19 \pm 0.06^{\mathrm{A}}$ & $0.34 \pm 0.09^{\mathrm{A}}$ \\
Bread+MC & $0.46 \pm 0.11^{\mathrm{A}}$ & $1.29 \pm 0.34^{\mathrm{A}}$ & $2.10 \pm 0.21^{\mathrm{B}}$ \\
Bread+oil & $4.81 \pm 0.35^{\mathrm{B}}$ & $4.55 \pm 0.36^{\mathrm{B}}$ & $7.15 \pm 0.69^{\mathrm{C}}$ \\
MC & $0.56 \pm 0.14^{\mathrm{A}}$ & nd & nd \\
Control oil & $0.57 \pm 0.13^{\mathrm{A}}$ & nd & nd
\end{tabular}

Any two means in the same column followed by the same letter are not significantly ( $\mathrm{P}$ e 0.05$)$ different according to the Tukey test. nd: no data 
Table 4. Fatty acid profile determination $\left(\mathrm{g} \mathrm{Kg}^{-1}\right)$ of the different chia oils extracted from breads, oil extracted from MC digested under simulated gastrointestinal conditions and oils extracted from containers inside bread crumb.

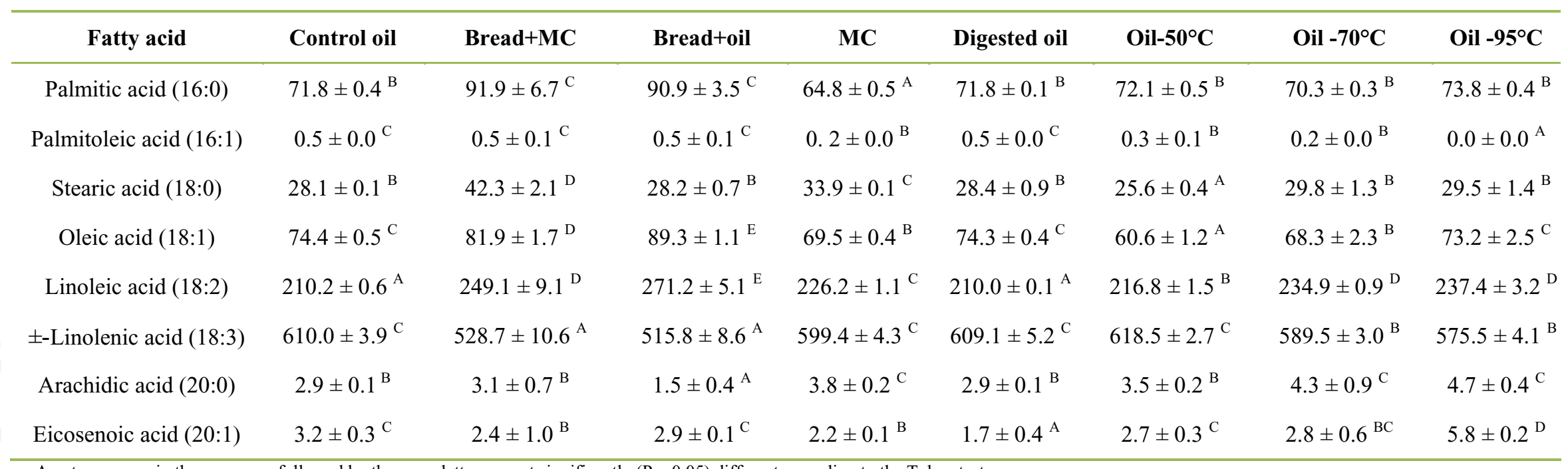

Any two means in the same row followed by the same letter are not significantly (P e 0.05$)$ different according to the Tukey test. 
Table 5. Sensory analysis results of samples respect to control bread where 5, 6 and 7 points represent "just right", "like it slightly" and "like it moderately", respectively.

\begin{tabular}{|c|c|c|c|c|c|}
\hline Sample & $\begin{array}{c}\text { General } \\
\text { aspect }\end{array}$ & Odor & Texture & Flavor & $\begin{array}{c}\text { General } \\
\text { acceptability }\end{array}$ \\
\hline Bread+MC & $6.85 \pm 1.23^{\mathrm{A}}$ & $5.10 \pm 1.08^{\mathrm{A}}$ & $6.39 \pm 0.99^{\mathrm{B}}$ & $5.48 \pm 1.16^{\mathrm{A}}$ & $6.06 \pm 1.41^{\mathrm{A}}$ \\
\hline Bread+oil & $6.25 \pm 1.32^{\mathrm{A}}$ & $5.73 \pm 1.23^{\mathrm{B}}$ & $5.75 \pm 1.22^{\mathrm{A}}$ & $5.5 \pm 1.23^{\mathrm{A}}$ & $6.26 \pm 1.12^{\mathrm{A}}$ \\
\hline
\end{tabular}

